\title{
TINGKAT TUTUR SEBAGAI SARANA PEMBENTUKAN PENDIDIKAN KARAKTER
}

\author{
Nurpeni Priyatiningsih \\ Program Studi Pendidikan Bahasa Jawa, Universitas Veteran Bangun Nusantara Sukoharjo \\ Email: nurpenipriyatiningsih@gmail.com
}

\begin{abstract}
Abstrak
Tingkat tutur atau dalam bahasa Jawa disebut unggah-ungguh adalah adat sopan santun, etika, tata susila, tatakrama berbahasa. Tingkat tutur tidak hanya terbatas pada bentuk tuturan tetapi juga menyangkut pada tindak tanduknya, yang dapat dikatakan sebagai patrap dan pocap. Tingkat tutur secara garis besar dibagi menjadi dua yaitu ragam ngoko dan ragam krama. Ragam ngoko sendiri dibagidua yaitu ngoko lugu dan ngoko alus. Demikian juga ragam krama terdiri dari dua yaitu ragamkrama lugu dan krama alus. Pendidikan bahasa Jawa mempunyai fungsi yang diarahkan untuk dua hal yaitu kultural dan edukatif. Penerapan tingkat tutur/unggah-ungguh melalui pendidikan bahasa Jawa bersifat vertikal artinya yang muda menggunakan ragam krama untuk menghormati yang tua/ dituakan, sebaliknya yang tua tidak boleh sewenang-wenang terhadap yang muda, yang demikian disebut keseimbangan. Konsep keseimbangan itu meliputi duduga, prayoga, watara dan reringa.Penerapan tingkat tutur/ unggah-ungguh dapat dijadikan sarana pembentukanpendidikan karakter.
\end{abstract}

Kata-kata kunci: Bahasa Jawa, Tingkat tutur, Pendidikan Karakter.

\section{SPEECH LEVEL AS THE MEANS OF CREATING CHARACTER EDUCATION}

\author{
Nurpeni Priyatiningsih \\ Javanese Language Education Study Program, Veteran Bangun Nusantara \\ University of Sukoharjo \\ Email: nurpenipriyatiningsih@gmail.com
}

\begin{abstract}
Speech level or in Javanese language called unggah-ungguh is decorum, ethics, morality order, and language etiquette. Speech level is not only limited to the form of speech but also pertaining to the conduct, called patrap and pocap. Overall, speech level is divided into to: ragam ngoko and ragam krama. Ragam ngoko itself is divided into two: ngoko lugu and ngoko alus. Similarly, ragam karma consists of two: krama lugu dan krama alus. Javanese language education has a function directed to two matters: cultural and educative. The application of speech level or unggah-ungguh through Javanese language education is vertical in nature, meaning that the young uses ragam krama to respect the old/elder; otherwise, the old cannot treat the young arbitrarily; this is called balance. The concept of balance involves duduga, prayoga, watara and reringa. The application of speech level/unggah-ungguh can be the means of creating character education.
\end{abstract}

Keywords: Javanese Language, Speech Level, Character Education 


\section{PENDAHULUAN}

Republik Indonesia ialah negara kepulauan terbesar di dunia yang terletak di Asia Tenggara, melintang di khatulistiwa antara benua Asia dan Australia serta antara Samudra Pasifik dan Samudra Hindia. Indonesia saat ini memiliki 33 propinsi dan memiliki 17.504 pulau yang menyebar di sekitar khatulistiwa. Hal ini menyebabkan Indonesia memiliki kekayaan sumber daya alam dan keanekaan hayati. Lebih dari 300 kelompok etnik hidup di Indonesia dan lebih dari 500 bahasa daerah tersebar di setiap pulau di 33 propinsi di Indonesia ( Takari,2008:21).

Tidak kurang dari 12\% dari seluruh bahasa di dunia ini terdapat di Indonesia. Summer Institute of Linguistics menginformasikan bahwa di Indonesia terdapat 731 bahasa, termasuk 5 bahasa yang telah punah. Jumlah penutur bahasa-bahasa tersebut beragam. Di Indonesia terdapat 13 bahasa terbesar dengan kriteria penuturnya minimal berjumlah 1 juta jiwa, diantaranya yaitu bahasa Jawa (75,2 juta ), Sunda (27 juta), dan Melayu (20 juta) (Sobarno, 2007:1).

Bahasa Jawa sejak lama adalah bahasa ibu bagi orang-orang Jawa yang tinggal, terutama di Propinsi Jawa Tengah, Daerah Istimewa Yogyakarta, dan Jawa Timur. Di Banten sebelah utara, di Lampung, di dekat Medan, dan daerah-daerah transmigrasi di beberapa pulau di Indonesia, terdapat pula orang-orang Jawa yang berbahasa Jawa ( Poedjosoedarma, 1979:1).

Bahasa Jawa, sejak lama digunakan sebagai bahasa pengantar suatu peradaban yang besar. Tradisi dan sastra tulis telah ada, dan terus- menerus terpelihara pada bahasa ini walaupun perubahan yang dialami baik oleh sistem, fonologi, morfologi, sintaksis, leksikon maupun ortografinya cukup tampak jelas. Namun kodifikasinya bahasa Jawa pada setiap masanya tampak mantap. Standarisasi dalam berbagai register serta dalam sistem strukturnya tampak jelas dan stabil.

Sejak tahun 1945 bahasa Jawa hanya berkedudukan sebagai bahasa daerah. Sejak saat itu beberapa fungsinya diambil alih oleh bahasa Indonesia di dalam soal-soal kedinasan, keilmuan dan beberapa aspek kehidupan yang bersifat resmi, terutama di kota-kota, tugas bahasa Jawa diambil alih bahasa Indonesia. Bahasa Jawa hanya berfungsi sebagai perantara aspek-aspek kehidupan yang bersifat tidak dinas, kedaerahan,kekeluargaan, dan tradisional. Sejak saat itu pula kegairahan dalam karya 
sastra tulis lambat laun menurun. Prestise bahasa Jawa baik di mata orang Jawa maupun di mata orang lain lambat laun menjadi pudar.

Akan tetapi ada beberapa faktor yang menyebabkan masih tetap terpeliharanya bahasa Jawa. Faktor-faktor itu adalah: (1) tradisi kesusasteraan Jawa yang sudah berurat dan berakar, (2) pecinta-pecinta bahasa Jawa yang masih cukup banyak dan masih giat mengusahakan agar bahasa Jawa terpelihara, (3) penutur bahasa Jawa sebagai bahasa ibu yang berjumlah sangat besar.

Terpeliharanya bahasa Jawa yang amat penting ialah suatu kenyataan bahwa bahasa Jawa masih tetap dipakai sebagai matapelajaran di pendidikan formal sejak SD sampai SMU/SMK. Hal ini seperti yang diamanatkan SK Gubernur Jawa Tengah Nomor 895-5/01/2005, Surat Edaran Walikota Surakarta Nomor 060/421/2011, BupatiBupati Kepala Daerah di kabupaten-kabupaten se-Eks Karesidenan Surakarta, dan kesepakatan tiga gubernur yaitu Gubernur Jawa Tengah, Daerah Istimewa Yogyakarta serta Jawa Timur yang menginstruksikan agar digunakan bahasa Jawa secara aktif dalam komunikasi lisan, baik komunikasi inter dan antar personal, maupun forumforum resmi, seperti rapat, dan kedinasan lainnya.

Ketika orang berbahasa Jawa mesti memperhatikan unggah-ungguh/ tingkat tutur.Tingkat tutur berkaitan erat dengan pendidikan budi pekerti, kesantunan, tatakrama dalam pergaulan. Fishman (dalam Wibowo, 2001: 5) mengatakan bahwa pemilihan bahasa tidak hanya ditentukan oleh faktor linguisik tetapi oleh faktor non linguistik seperti faktor sosial dan dan faktor situasional. Selanjutnya situasi pergaulan bisa resmi,formal,berjarak atau tak resmi, non formal, akrab. Ketika penutur bahasa Jawa bergaul dalam berbagai situasi tentuakan menentukan ragam yang dipilihnya.

Rumusan masalah dalam tulisan ini adalah sebagai berikut. (1) Bagaimana ragam tingkat tutur dalam bahasa Jawa? dan (2) Apakah tingkat tutur bahasa Jawa dapat sebagai sarana pembentukan pendidikan karakter?

\section{TINGKAT TUTUR BAHASA JAWA}

Tingkat tutur (speech level) dalam bahasa Jawa disebut unggah-ungguh atau undha usuk adalah variasi bahasa yang pembedaannya ditentukan perbedaan sikap santun yang ada pada diri pembicara dan lawan bicara( Poedjosoedarma, 1979:2). Tingkat tutur merupakan sistem penyampaian rasa kesopanan di dalamnya terkandung 
kosa kata, sintaksis, morfologi dan fonologi. Kosa kata hanyalah inventarisasi kata-kata yang masing-masing memiliki arti yang berbeda tingkat kesopanannya. Pemilihan penggunaan kosa kata perlu diperhatikan karena kekurangtepatan pemilihan kosa kata mempengaruhi penggunaan tingkat tutur yang dapat berakibat kurang sopan pada lawan bicara ( Arka, 2005: 175). Tingkat tutur juga menyangkut: (a) apa sebaiknya dikatakan pada waktu dan keadaan tertentu, (b) ragam sewajarnya dipakai, (c) kapan dan bagaimana menggunakan giliran berbicara dan menyela pembicaraan orang lain dan juga, (d) kapan harus diam ( Nababan, 1993:53).

Ditinjau dari segi sosiolinguistik setiap bahasa memiliki stratifikasi tutur. Stratifikasi tutur adalah suatu sistem bertutur yang mempunyai kata-kata yang jelas terhadap formalitas dan rasa hormat yang ingin ditunjukkan kalau bertutur, makin tinggi pula kesopanan yang ditunjukkan dalam bertutur kata (Wahab, 1991: 57). Oleh karena itu ketika seseorang ingin bertutur menggunakan bahasa Jawa seperti halnya bertutur dalam bahasa lain, mesti memperhatikan tentang apa, kepada siapa, kapan, dimana, bagaimana dan suatu komunikasi terjadi ( Pride, 1979: 9).

Menyadari betapa sulit dan rumit pembagian tingkat tutur bahasa Jawa, beberapa pakar yang lebih muda, kemudian mencoba menyederhanakannya. Di antaranya adalah Harjana Harjawijana dan Supriya/ 2001, Sudaryanto/1987, Sri Satriya Tjatur Wisnu Sasangka/2004 membagi tingkat tutur bahasa Jawa menjadi 2 yaitu: (1) Ngoko yang terdiri dari: (a) ngoko lugu dan (b) ngoko alus, (2) Krama yang terdiri dari: (a) krama lugu dan (b) krama alus. Berdasarkan perubahan tingkat tutur tersebut mempertimbangkan agar mudah bagi penutur bahasa Jawa secara umum, terlebih- lebih bagi generasi mudanya. Mereka tidak lagi takut berbahasa Jawa karena tingkat tuturnya yang dirasa tidak lagi sulit dan rumit.Penyederhanaan tersebut dilakukan berdasarkan kenyataan di lapangan dan pertimbangan praktis lainnya. Di antaranya ngoko kasar dan krama desa tidak perlu dijarkan dengan sengaja karena anak dapat mengenalinya dari lingkungan masyarakat dalam hidup sehari-hari. Di samping itu juga ada sifat tidak baku. Basa kedhaton dapat diabaikan karena kenyataannya jarang dipakai termasuk di lingkungan kraton sekalipun ( Subroto, 2013:11). 


\section{LEKSIKON DALAM BAHASA JAWA}

Menurut Sasangka ( 2004: 25) leksikon merupakan komponen bahasa yang memuat semua informasi tentang makna dan pemakaian kata dalam satuan bahasa. Selain itu leksikon juga merupakan kekayaan kata yang dimiliki suatu bahasa. Jika dilihat dari segi bentuk leksikon bahasa Jawa dapat dibedakan menjadi enam yaitu leksikon: (1) ngoko, (2) madya, (3) krama, (4) krama andhap, (5) krama inggil, dan (6) netral. Sejalan dengan pendapat Sasongko (2008: 33-34) juga membagi leksikon bahasa Jawa berdasar bentuknya. Leksikon tersebut adalah: (1)madya, (2) krama, (3)krama inggil, (4) krama andhap, (5) ngoko, dan (6)netral

\section{Leksikon Ngoko}

Leksikon ngoko merupakan kosa kata dasar, asli yang nantinya akan membentuk kosa kata krama dan krama inggil. Tetapi bukan berarti semua kosa kata ngoko pasti memiliki padanan dalam kosa katakrama, maupun krama inggil. Atau suatu kata hanya memiliki ngoko dan krama inggil saja. Contohnya kata"cebol"," bingung", "bagus", "buku”. Kata-kata tersebut tidak memiliki padanan dalam leksikon krama dan krama inggil.

\section{Leksikon Krama}

Leksikon krama merupakan bentuk halus dari kosa kata ngoko. Kosa kata krama dibagi menjadi dua yaitu kosa kata krama baku (tiyang sepuh)dan kosa kata krama desa (tiyang sepah).Krama baku adalah kosa kata krama yang sesuai dengan kaidah dan tatabahasa Jawa yang benar yang bisa dilihat dalam kamus. Krama desa adalah kosa kata yang digunakan oleh masyarakat pedesaan dikarenakan mereka tidak memahami tata bahasa yang benar

\section{Leksikon Krama Inggil}

Leksikon krama inggil hanya dapat digunakan untuk orang lain baik untuk orang yang diajak bicara $(\mathrm{O} 2)$ maupun orang dibicarakan $(\mathrm{O} 3)$, untuk diri sendiri $(\mathrm{O} 1)$ tidak dibenarkan menggunakan leksikon ini. Misalkan leksikon lunga"pergi"(ngoko) menjadi tindak (krama inggil). Hal ini dapat dilihat pada kalimat berikut: Mas Yoyok arep tindak Surabaya ( Mas Yoyok akan pergi ke Surabaya).

\section{Leksikon Madya}

Leksikon madyamerupakan kosa kata yang memiliki kadar kehalusansedang, antarangoko dan krama. Kosa kata madya biasanya digunakan dalamsituasi tidak resmi 
(informal). Kosa kata madya kalau digunakan dalam tuturan terasa kurang halus. Ciri kosa kata madya adalah adanya penyingkatan pada kosa kata tersebut. Misalnya kosa $\operatorname{kata}($ menapa...napa) , (rumiyin...riyin)

\section{Leksikon Krama Andhap}

Leksikon krama andhap merupakan kosa kata yang digunakan untuk menghormati orang lain dengan cara merendahkan diri sendiri. Leksikon krama andhap hanya digunakan untuk diri sendiri tidak boleh digunakan untuk orang lain.Misalnya kosa kata matur"bicara”, ndherek "ikut”, sowan"menemui”

\section{Leksikon Netral}

Leksikon netraladalah leksikon yang dapat digunakan pada semua leksikon. Kosa kata netral dapat digunakan untuk diri sendiri dan orang lain. Contoh kosa kata netral: tilpun, tempe, laptop, komputer, gubernur. Umumnya kosa kata netral adalah kosa kata serapan dari bahasa Indonesia atau bahasa asing yang belum ada padanannya.

Sedangkan jika dilihat dari segi makna atau dari sudut pragmatis dan/atau semantis, leksikon bahasa dibedakan menjadi tiga yaitu leksikon: 1) halus, 2) biasa, dan 3) kasar.Leksikon halus merupakan leksikon yang merupakan leksikon yang mencerminkan kesantunan. Leksikon biasa adalah leksikon yang tidak mengungkapakan makna kasar dan halus suatu tuturan. Sedangakan leksikon kasar adalah leksikon yang mengungkapkan makna kasar yang tidak menunjukan kesantunan. Misalnya leksikon minggat"pergi”, modar"mati”, picek"buta”

\section{RAGAM TINGKAT TUTUR BAHASA JAWA}

Bahasa Jawa merupakan bahasa yang mengenal adanya tingkat tutur atau undhausuk basa atau unggah-ungguh basa. Adanya tingkat tutur dalam bahasa Jawa merupakan adat sopan santun berbahasa Jawa. Adat sopan santun ini mencerminkan perilaku kebahasaan yang sebenarnya juga tercermin dari perilaku masyarakatnya.

Tingkat tutur bahasa Jawa yang disusun oleh Poedjasoedarma (1979:13) disebutkan tingkat tutue bahasa Jawa terdiri dari 3 tingkatan yang masih dipilih-pilih menjadi sembilan bentuk yakni:

(a) Basa Ngoko

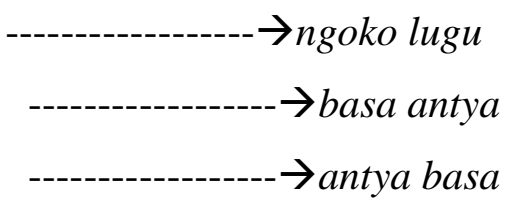


(b) Basa Madya

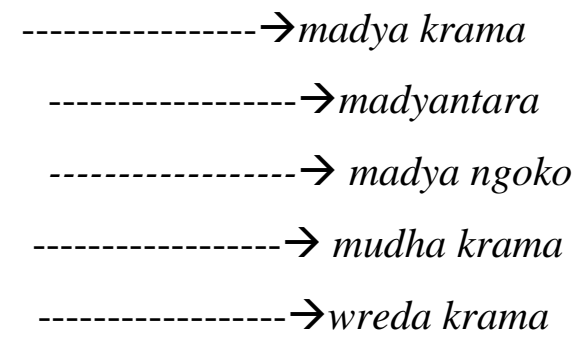

Bahasa bersifat dinamis, artinya akan selalu berubah mengikuti perkembangan jaman. Hal ini berlaku juaga untuk bahasa Jawa. Pembagian undha-usuk/ unggahungguh/tingkat tutur yang sangat banyak tersebut akhirnya mengerucut menjadi dua yaitu ngoko dan krama. Perubahan unggah-ungguh menjadi lebih sederhana sangat logis. Hal ini seiring dengan perubahan sistem pemerintahan, dari zaman monarkhi, feodalisme ke jaman demokratis. Perubahan jaman tersebut berdampak pada perubahan polotik, ekonomi termasuk unggah-ungguh.

Pembagian tingkat tutur/unggah-ungguh bahasa Jawa yang sekarang digunakan dalam proses belajar mengajar di sekolah mengacu pada pendapat Sudaryanto (1989) dan Ekowardana (1993) yang pada dasarnya memiliki kesamaan yaitu: 1) ngoko lugu, 2) ngoko alus, 3) krama lugu, 4) krama alus.Jadi secara garis besar tingkat tutur bahasa Jawa dibedakan menjadi 2 bentuk yaitu ragam ngoko dan ragam krama. Jika terdapat tingkat tutur ragam lain dipastikan bahwa bentuk tersebut hanya merupakan varian dari ragam ngoko dan krama. Kedua bentuk tingkat tutur tersebut akan diuraikan berikut ini: 1. Ragam Ngoko

Yang dimaksud ragam ngoko adalah bentuk unggah-ungguh bahasa Jawa yang berintikan leksiko ngoko, atau yang menjadi unsur inti di dalam ragam ngoko adalah leksikon ngoko bukan yang lain. Afiks yang muncul dalam ragam inipun semuanya berbentuk ngoko ( misalnya afiksdi-, -e dan -ake). Ragam ngoko dapat digunakan untuk mereka yang sudah akrab dan oleh mereka yang merasa dirinya lebih tinggi status sosialnya dari pada lawan tuturnya (mitra tutur).

Ragam ngoko mempunyai dua bentuk varian, yaitu ngoko lugu dan ngoko alus. Uraian berikut ini akan membahas hal itu:

\subsection{Ngoko Lugu}

Yang dimaksud ngoko lugu adalah bentuk tingkat tutur bahasa Jawa yang semua kosa katanya berbentuk ngoko dan netral (leksikon ngoko dan netral) tanpa terselip 
leksikon krama, krama inggil, atau krama andhap, baik persona pertama (O1), persona kedua $(\mathrm{O} 2)$ maupun persona ketiga (O3). Perhatikan contoh berikut.

a) Aku kulina turu awan ( Saya biasa tidur siang)

b) Kowe kulina turu awan ( Kamu biasa tidur siang)

c) Dheweke kulina turu awan (Dia biasa tidur siang)

Butir turu "tidur" pada kalimat a) merupakan leksikon ngoko yang dapat digunakan oleh persona kedua kowe"kamu”b) dan oleh persona ketiga dheweke "dia”, serta kulina “ biasa”, dan awan”, semuanya merupakan leksikon ngoko.

\subsection{Ngoko Alus}

Yang dimaksud dengan ngoko alus adalah bentuk unggah-ungguh yang di dalamnya bukan hanya terdiri atas leksikon ngoko dan netral saja, melainkan juga terdiri atas leksikan krama inggil, krama andhap, dan krama. Namun leksikon krama inggil, krama andhap atau leksikon krama yang muncul di dalam ragam ini sebenarnya hanya digunakan untuk menghormati mitra wicara (O2 atau O3).

Leksikon krama inggil yang muncul di dalam ragam ini biasanya hanya terbatas pada kata benda (nomina), kata kerja (verba), atau kata ganti orang (pronomina). Jika leksikon krama adhap muncul di ragam ini, biasanya leksikon itu berupa kata kerja, dan jika leksikon krama muncul dalam ragam ini, leksikon itu biasanya berupa kata kerja atau kata benda.

a) Mentri pendidikan sing anyar iki asmane sapa? (Menteri pendidikan yang baru siapa namanya?)

b) Simbah engko arep tindak karo sapa? (Nenek nanti pergi dengan siapa?)

c) Penjenengan sida ngajak aku apa ora Mas? (Anda jadi mengajak saya apa tidak Mas)

d) Aku mengko arep nyuwun dhit nyang bu Eri (Saya nanti akan minta uang kepada bu Eri)

e) Dhik seratan penjenengan akeh sing seneng, lho! (Dik tulisan Anda banyak yang suka lho!)

f) Kae Bapakmu gek maos neng kamar (Itu Bapakmu sedang membaca di kamar)

Tampak leksikon asmane"namanya"(nomina) pada a), tindak"pergi"(verba) pada

b) dan penjenengan "Anda" (pronomina) pada c) dan e) merupakanleksikon krama inggil; leksikon nyuwun"meminta" (verba) pada d) merupakan leksikon krama andhap; 
leksikon seratan "tulisan" (nomina) pada e) dan maos"membaca" (verba) pada f). Leksikon lain yang terdapat pada contoh di atas, selain leksikon netral dan leksikon tindak, asmane, penjenengan, nyuwun, seratan, dan maos, semuanya termasuk leksikon ngoko.

Meskipun terdapat leksikon krama, krama inggil atau krama andhap, kalimat d) dan f) tetap berstatus sebagai ragam ngoko tetapi ragam ngoko yang halus. Pemunculan leksikon krama, krama inggil atau andhap dalam kalimat tersebut hanya mampu mengubah bentuk ngoko lugu menjadi ngoko alus, tetapi tidak mampu mengubah status ragam ngoko itu menjadi ragam krama.

Afiks yang digunakan dalam ngoko alus meskipun melekat pada leksikon krama inggil, krama andhap, dan krama tidak jauh berbeda bentuknya dengan afiks yang melekat pada ngoko lugu, yaitu menggunakan afiks penanda leksikon ngoko (di-,-e dan $-n e)$

\section{Ragam Krama}

Yang dimaksud dengan ragam krama adalah bentukunggah-ungguh bahasa Jawa yang berintikan leksikon krama, atau yang menjadi unsur inti di dalam ragam krama adalah leksikon krama bukan leksikon yang lain. Afiks yang muncul dalam ragam inipun semuanya berbentuk krama (misalnya afiks dipun-, -ipun, dan-aken). Ragam krama digunakan oleh mereka yang belum akrab dan oleh mereka yang merasa dirinya lebih rendah status sosialnya dari pada lawan bicara. Ragam krama mempunyai dua bentuk varian, yaitu krama lugu dan krama alus.

\subsection{Krama Lugu}

Istilahlugupada krama lugutidak didefinisikan sepertilugu padangoko yang ngoko lugu. Makna lugu pada ngoko lugu mengisyaratkan makna bahwa bentuk leksikan yang terdapat di dalam unggah-ungguh tersebut semuanya berupa ngoko. Sementara itu, lugu dalam krama lugu tidak diartikan sebagai suatu ragam yang semua ragam kosa katanyanya terdiri atas leksikon krama, tetapi digunakan untuk menandai suatu ragam yang kosa katanya terdiri atas leksikon krama madya, netral atau ngoko dan ditambah dengan leksikon krama inggil atau krama andhap. Meskipun begitu yang menjadi leksikon inti dalam krama lugu adalah leksikon krama, madya, dan netral, sedangkan leksikon krama inggil atau andhap yang muncul dalam ragam ini hanya 
digunakan untuk menghormati lawan bicara. Kata tugas yang muncul dalam ragam inipun menurut Poedjasoedarma(1979:12) biasanya berupa leksikon madya.

Secara semantis ragam krama lugu dapat didefinisikan sebagai suatu bentuk ragam krama yang kadar kehalusannya rendah.Meskipun begitu, jika dibandingkan dengan ngoko alus, ragam krama lugu tetap menunjukkan kadar kehalusan. Masyarakat awam ragam ini dengan sebutan krama madya.Beberapa contoh krama lugu bisa dilihat berikut ini.

a) Sing dipilih Sigit niku jurusan Jurnalistik utawi Perhotelan. (Yang dipilih Sigit niku jurusan Jurnalistik atau Perhotelan).

b) Sakniki nek boten main plesetan, tiyang sami males nonton kethoprak. (Sekarang jika tanpa plesetan, orang males nonton kethoprak).

c) Bank ngriki boten saged ngijoli dhuwit dholar. (Bank di sini tidak bisa menukar uang dolar.)

Butir utawi "atau” a), boten "tidak" b), tiyang “ orang", sami “pada” b), ngriki “ di sini”, dan saged "dapat/bisa” c) merupakan leksikon krama. Sementara itu, leksikon lain seperti jurusan Jurnalistik, perhotelan, main plesetan, kethoprak, bank dan dholar semuanya merupakan leksikon netral karena bentuk-bentuk itu tidak mempunyai padanan bentuk krama, krama inggil atau madya.

Leksikon krama inggil dan krama andhap yang muncul dalam tingkat tutur ini digunakan untuk menghormati mitrawicara. Hal itu tampak pada contoh di bawah ini.

a) Penjenengan napa empun nate tindak teng Rembang? (Sudah pernahkah Anda pergi ke Rembang?)

b) Ngga Kang, niku nyamikane mang dhahar, ampun diendelake mawon. (Silakan Kak, itu kudapannya dimakan, jangan didiamkan saja)

c) Yen angsal mang suwunke gangsal iji mawon kangge kula. (Jika boleh, Anda mintakan lima biji saja untuk saya).

Butir penjenengan "Anda" dan tindak " pergi" pada m) serta dhahar "makan" pada a) merupakan leksikon krama inggil yang digunakan oleh O1 untuk penghormatan kepada lawan bicara, yaitu penghormatan kepada penjenengan "Anda" pada b) dan kepada mang "kamu" pada n). Butir suwunke/suwunake "mintakan" pada c) merupakan leksikon krama andhap yang digunakan oleh O1, yaitu kula " saya” pada c). Jika butir 
suwunke pada mang suwunke diubah menjadi pundhut" sehingga menjadi mang pundhutke seperti contoh berikut.

d) Yen angsal, mang pundhutke gangsal iji mawon kangge kula. ( Jika boleh, Anda mintakan lima biji saja untuk saya). Kalimat tersebut jadi tidak berterima. Ketidakberterimaannya itu dikarenakan O1 (kula) menggunakan bentuk krama inggil pundhut "minta, beli,ambil" untuk diri sendiri.

\subsection{Krama Alus}

Yang dimaksud dengan krama alus adalah bentuk unggah-ungguh bahasa Jawa yang semua kosa katanya terdiri atas leksikon krama dan dapat ditambah dengan leksikon krama inggil atau krama andhap. Meskipun begitu, yang menjadi leksikon inti dalam ragam ini hanyalah leksikon yang berbentuk krama. Leksikon madya dan leksikon ngoko tidak pernah muncul di dalam tingkat tutur ini. Selain itu, leksikon krama inggil atau krama andhap secara konsisten selalu digunakan untuk penghormatan terhadap mitra wicara.

Secara semantis ragam krama alus dapat didefinisikan sebagai suatu bentuk ragam krama yang kadar kehalusannya tinggi.

a) Aksara Jawi punika menawi kapangku dados pejah (Aksara Jawa kalau dipangku malah mati)

b) Ingkang Sinuhun tansah angengetaken bilih luhur nisthaning asma gumanting wijining pangandikan (Sang raja selalu mengingatkan bahwa baik buruknya nama seseorang bergantung pada apa yang diucapkan)

c) Para miyarsa, wonten ing giyaran punika kula badhe ngaturakaen rembag bab kasusastran Jawi (Para pendengar dalam kesempatan ini saya akan berbicara tentang kesusasteraan Jawa).

Butir Jawi "Jawa", punika" itu/ini”, menawi "jika", dados"jadi”, dan pejah'Mati" pada a); butir ingkang "yang" dan angengetaken "mengingatkan" pada b); butir wonten" ada", giyaran" siaran", kula "saya", badhe"akan", dan rembag "pembicaraan" pada c) semuanya merupakan leksikon krama. Butir asma "nama" dan pangandikan 'perkataan' pada b) merupakan leksikon krama inggil. Sedangkan butir ngaturaken "memberikan?membicarakan" pada c) merupakan leksikon krama andhap. Sementara itu, butir aksara "huruf" dan kapangku "dipangku pada a), butir tansah "selalu" , nisthaning "hinanya", gumantung"bergantung" dan wijining 
"buahnya/hasilnya" pada b), serta serta butir para"para", bab "bab", dan kesusastran "kesusasteraan" pada c) merupakan leksikon netral yang tidak mempunyai padanan bentuk leksikon lain. Dalam tingkat tutur ini afiks dipun-, -ipun dan -aken cenderung lebih sering muncul dari pada afiks di-,-e dan -ak

\section{TINGKAT TUTUR BAHASA JAWA SEBAGAI SARANA PEMBENTUKAN PENDIDIKAN KARAKTER}

\section{Pengertian Karakter}

Pengertian karakter menurut Kamus Besar Bahasa Indonesia dapat dimaknai sebagai sifat- sifat kejiwaan, akhlak atau budi pekerti yang membedakan seseorang dengan yang lain (Depdikbud, 1998: 389).Sementara Koesoemo (2012: 56) mendefinisikan karakter sebagai sebuah kondisi dinamis struktur antropologis individu, yang tidak mau sekedar berhenti atas determinasi kodratinya, melainkan juga sebuah usaha untuk hidup semakin integral mengatasi determinasi alam dalam dirinya demi proses penyempurnaan dirinya secara terus-menerus. Selanjutnya menurut pengamatan filusuf kontemporer Michael Novak (dalam Lickona, 2013:72) karkater adalah perpaduan harmonis seluruh budi pekerti yang terdapat dalam ajaran-ajaran agama, kisah-kisah sastra, ceritera-ceritera orang bijak dan orang-orang berilmu, sejak jaman dahulu hingga sekarang. Kemudian dijelaskan pada bagian lain dalam Desain Induk Pendidikan Karakter, dikatakan bahwa karakter menunjukkan bagaimana seseorang bertingkah laku. Apabila seseorang bertingkah laku tidak jujur, kejam, atau rakus dapat dikatakan orang tersebut memanifestasikan orang tersebut perilaku buruk. Sebalikanya, apabila seseorang berperilaku jujur, bertanggung jawab, suka menolong, tentulah orang tersebut memanifestasikan karakter mulia.Seseorang baru disebut orang yang berkarakter apabila tingkah lakunya sesuai dengan kaidah moral (Kemendikbud, 2011:11).

\section{Pendidikan Karakter}

Pendidikan karakter menurut Pusat Kurikulum dan Perbukuan merupakan pendidikan nilai, pendidikan budi pekerti, pendidikan moral, pendidikan watak yang bertujuan untuk mengembangkan kemampuan peserta didik untuk memberikan keputusan baik-buruk, memelihara apa yang baik dan mewujudkan kebaikan itu dalam kehidupan sehari-hari dengan sepenuh hati. Atas dasar itu, pendidikan karakter tiadak 
hanya sekedar hanya mengajarkan mana yang benar dan mana yang salah, lebih dari itu pendidikan karakter menanamkan kebiasaan (habituation), tentang hal yang baik sehingga pesrta didik menjadi paham (domain kognitif),tentang mana yang baik dan salah, mampu merasakan (domain afektif) dan nilai yang baik dan bisa melakukannya(domain psikomotor). Dengan kata lain pendidikan karakter yang baik harus melibatkan bukan saja aspek pengetahuan yang baik (moral knowing), akn tetapi juga merasakan dengan baik (moral feeling), dan perilaku yang baik (moral action). Pendidikan karakter menekankan pada habit atau kebiasaan yang terus menerus dipraktikan dan dilakukan ( Kementrian Pendidikan Nasional, 2011: 10 ).

\section{Pendidikan Bahasa Jawa}

Pendidikan bahasa Jawa adalah pendidikan yang diarahkan kepada terjadinya transfer nilai-nilai budaya di dalam kehidupan berbudaya Jawa. Bahasa Jawa merupakan bagian integral kebudayaan bangsa Indonesia, dan karenanya pembinaan dan pengembangannya tetap dalam bingkai keindonesiaan. Artinya pembinaan dan pengembangan bahasa Jawa harus dilakukan seiring dengan pembinaan dan pengembangan bahasa nasional. Bahasa Jawa tumbuh sebagai identitas diri dengan tetap mempertahankan nilai-nilai luhur yang terkandung di dalamnya dan bahasa Indonesia tumbuh sebagai perekat bangsa. Selain itu, bahasa Jawa tidak dapat dilepaskan dari kebudayaan Jawa karena bahasa Jawa merupakan bingkai kebudayaan Jawa sekaligus sebagai hasil budaya Jawa.

Bahasa Jawa sebagai bahasa daerah memiliki tiga fungsi utama yaitu: 1) fungsi kebudayaa, 2) fungsi komunikasi dan, 3) fungsi pendidikan. Fungsi kebudayaandiarahkan untuk tujuan pelestarian budaya. Fungsi komunikasi diarahkan untuk tujuan alat perhubungan di dalam keluarga dan masyarakat Jawa. Adapunfungsi pendidikan diarahkan untuk dua hal yaitukultural dan edukatif.Tujuan edukatif diarahkan agar supaya seseorang dapat menggunakan bahasa Jawa secara baik dan benar, dan untuk pemerolehan nilai-nilai untuk keperluan keperluanpembentukan kepribadian dan identitas bangsa. Tujuan kultural diharapkan agar melalui pendidikan dapatdigali dan ditanamkan kembali nilai-nilai budaya Jawa sebagai upaya untuk membangun identitas danmenanamkan filter dalam menyeleksi pengaruh budaya luar. Untuk menghadapisituasi yang serba merepotkan dan membingungkan ini diperlukan 
penerapanfungsi bahasa Jawa sebagai sarana pendidikan.Pendidikan yang terkandung dalam bahasa Jawa adalah pendidikan budi pekerti dan pendidikan karakter.

3. Penerapan Tingkat Tutur Bahasa Jawa Sebagai Sarana Pembentukan Pendidikan Karakter

Tingkat tutur atau dalam bahasa Jawa disebut unggah-ungguh, tidak hanya terbatas pada tuturan tetapi juga pada tindak tanduknya, yang dapat dikatakan sebagaipatrapdan pocapan.Tingkat tutur bahasa Jawa tidak hanya menyangkut bentuk bahasanya tetapi juga mengingat pada tindak tanduk atau patrapnya, seperti yang dikatakan Poerwadarminta( 1939: 38) bahwa tingkat tutur adalah tata pranataning basa miturut lungguhing tata krama, dan tata krama: unggah-ungguhing ginem tuwin tindak tanduk. Dengan demikian tingkat tutur bahasa Jawa merupakan pedoman atau aturan tentang perilaku berbahasa yang harus mengingat pada pemilihan bentuk bahasa dan dibarengi dengan tindak tanduk yang sesuai.

Penerapan tingkat tutur/unggah-ungguh bahasa Jawa sebagai bentuk perwujudan sopan-santun di masyarakat Jawa yang terdiri dari patrap dan pocapan tersebut adalah suatu tata cara atau aturan yang secara turun temurun dan berkembang dalam suatu budaya budaya masyarakat, yang bermanfaat dalam pergaulan dengan orang lain agar terjalin hubungan akrab, pengertian, saling menghormati menurut adat yang telah ditentukan. Ada pendapat bahwa baik buruknya tingkah laku anak merupakan cerminan tingkah laku orang tuanya sendiri. Kalau orang tua dan masyarakat berhasil menjalankan perannya untuk menjadi cerminan perilaku sopan santun generasi penerusnya, keinginan pendidikan Ki Hajar Dewantara dengan ungkapan "Ing ngarsa sung tuladha" ( di depan memberi tutunan) dapat terwujud. Pendidikan di sini dimaksudkan sebagai "menuntun" segala kodrat yang ada pada anak-anak itu agar mereka sebagai manusia dan anggota masyarakat dapat mencapai keselamatan dan kebahagiaan yang setinggi-tingginya. Kodrat manusia dari lahir sampai akhir hayatnya dibagi menjadi empat tahap yaitu: masa muda, masa dewasa, masa tua/merenung, dan masa mengesampingkan keduniaan. Masing-masing tahap memiliki tugas dan kewajiban yang mesti dilaksanakan dengan sebaik-baiknya.Tugas dan kewajiban masa muda merupakan bekal untuk memasuki masa dewasa, dan masa dewasa untuk bekal memasuki masa tua dan masa tua untuk memasuki masa meninggalkan keduniaan. Pengertian pendidikan untuk menuntun anak menuju kepada pencapaian keselamatan 
dan kebahagiaan setinggi-tingginya kodrat manusia yang terdiri dari empat tingkatan tersebut yang merupakan perjalanan yang sangat panjang. Pencapaian keselamatan dan kebahagiaan setinggi-tingginya merupakan perjalanan panjang yang dapat disejajarkan dengan pencapaian menjadi makhluk individual, makhluk sosial dan makhluk moral yang pada dasarnya sebagai makhluk tidak dapat memilih salah satu atau salah dua ataupun memilih yang menguntungkan. Sebagai manusia kita tidak dapat bertindak berdasarkan kemauan kita sendiri, kita hidup di masyarakat yang tidak dapat dipisahkan dari kehidupan anggota masyarakat yang tidak dapat dipisahkan dari anggota masyarakat lainnya. Di sinilah pentingnya tingkat tutur, unggah-ungguh atau sopan santun diterapkan dengan baik.

Penerapan tingkat tutur/unggah-ungguh dalam budaya Jawa bersifat vertikal, yang muda harus menggunakan bentuk krama untuk menghormatiorang tua atau yang lebih tua atau yang dituakan. Tetapi yang tua tidak boleh sewenang-wenang terhadap yang lebih muda, yang disebut keseimbangan. Konsep keseimbangan itu meliputi duduga, prayoga, watara dan reringa. Dudugaadalah tingkah laku yang mempertimbangkan masak-masak sebelum melangkah. Prayoga mempertimbangkan baik buruknya. Watara, dipikir masak-masak sebelum memutuskan dan reringa adalah hati-hati sebelum yakin betul keputusan itu. Keempat konsep sopan santun tersebut akan membentuk sifat yang baik untuk memiliki orang dalam mengarungi kehidupan ini yakni rereh (sabar mengekang diri), ririh (tidak tergesa-gesa), dan ngati-ati (berhatiati) ( Suharti,1998: 34-35) Dengan demikian sebelum seseorang bertindak sebetulnya sudah melalui proses pemikiran atau menggunakan pertimbangan-pertimbangan tertentu agar tidak terjadi salah faham.

\section{PENUTUP}

\section{Simpulan}

Pendidikan karkter adalah pendidikan yang diarahkan pada karakter, jati diri atau identitas.Pembentukan pendidikan karakter ini dapat dilaksanakan lewat pembelajaran bahasa Jawa dengan menerapkan penggunaan tingkat tutur/ unggahungguh sesuai situasi dan konteks. Pendidikan karakter lewat penerapan tingkat tutur dalam berbahasa Jawa adalah realisasi sopan santun,etika,tata krama. 
Bila direnungkan dengan baik, sesungguhnya tingkat tutur/unggah-ungguh dapat dijadikan sarana pembentukan pendidikan karakter, identitas diri, dan jati diri bangsa. Hal ini dimaksudkan untuk menangkal pengaruh derasnya arus global yang tidak sesuai dengan budaya Jawa khususnya maupun budaya Indonesia pada umumnya

2. Saran.

Pembentukan pendidikan karakter ini dapat dilaksanakan tidak hanya lewat pembelajaran bahasa Jawa secara formal di sekolah dengan menerapkan penggunaan tingkat tutur sesuai situasi dan konteks, melainkan melalui pendidikan informal dan non-formal.Melalui pendidikan informal di dalam keluarga karena di sinilah pendidikan pertama dan utama terjadi. Misalnya orang tua memberi keteladanan, model ketika bertutur kata, bersikap dengan para putranya.Kecuali itu melalui pendidikan non-formal para tokoh masyarakat dan tokoh agama ikut bertanggung jawab misalnya keteladanan dalam bertutur kata , bergaul, sopan santun ataupun bertatakrama.

\section{DAFTAR PUSTAKA}

Arka, I.W.2005. Speech Level, Social Predicates and Pragmatic Structure in Balinese: A Lexical Approach. International Pragmatics Association: Journal Pragmatics 15 (2/3) 169-203

Departemen Pendidikan dan Kebudayaan. 1998, Kamus Besar Bahasa Indonesia. Jakarta: Balai Pustaka

Fishman, J.A. 1972. The Sociology of Language. Rawly Massachusett: Newbury House

Koesoema, A Doni. 1212. Pendidikan Karakter Utuh dan Menyeluruh. Yogyakarta: Kanisius

Kridalaksana, Harimurti.2008. Fungsi Bahasa dan Sikap Bahasa. Ende: Nusa Indah

Nababan. PWJ, 1993. Sosiolinguistik: Suatu Pengantar. Jakarta: Gramedia Pustaka

Poedjosoedarma, Soepomo. 1979. Morfologi Bahasa Jawa. Jakarta: Pusat Pembinaan dan Pengembangan Bahasa, Depdikbud Tingkat Tutur Bahasa Jawa. Jakarta: Depdikbud

Poerwadarminta. 1939. Baoesastra Djawa. Batavia: J.B. Wolters UitgeversMaatschappij N. V. Groningen 
Kawruh: Journal of Language Education, Literature, and Local Culture

Volume 1, Nomor 1, 2019

Pride, JP and Janet Holmes. 1979. Sociolinguistics. Middlesex: Penguin Brooks Inc

Sasongko, Sri Satriyo Tjatur Wisnu. 2004. Unggah-Ungguh Bahasa Jawa. Jakarta: Yayasan Pramalingua

Subroto, Edi.2013. Tingkat Tutur Krama di Kalangan Generasi Muda Jawa. Online: http://sastra.um.ac.id/wp-content/upload/2010/01/020

Sobarno, Cece.2007. Bahasa Sunda Sudah di Ambang Pintu Kematiankah? Bandung: Fakultas Sastra, Universitas Padjajaran

Suharti. 1998. Perilaku Berbahasa Jawa Mahasiswa Ekspresi Lisan Program Studi Pendidikan Bahasa Jawa FPBS IKIP Yogyakarta. Jakarta: IKIP Jakarta

Takari, Muhammad dkk. 2008. Masyarakat Kesenian di Indonesia. Sumatra Utara: Fakultas Sastra USU

Wibowo, Wahyu. 2001. Manajemen Bahasa. Jakarta: Gramedia Pustaka. 